\title{
New challenges in diagnosis of haemoglobinopathies: Migration of populations
}

\author{
John Old, Adele Timbs, Janice McCarthy, Alice Gallienne, Melanie Proven, \\ Michelle Rugless, Herminio Lopez, Jennifer Eglinton, Dariusz Dziedzic, \\ Matthew Beardsall, Mohamed S.M. Khalila, Shirley Henderson
}

John Radcliffe Hospital, Oxford, UK

\begin{abstract}
The current influx of economic migrants and asylum seekers from countries with a high prevalence of haemoglobinopathies creates new challenges for health care systems and diagnostic laboratories. The migration of carriers introduces new and novel haemoglobinopathy mutations to the diagnostic repertoire of a laboratory, often creating new pressures to improve and update the carrier screening technology and diagnostic scope. For antenatal screening programmes, the marriage of partners from different ethnic groups can lead to the risk of compound heterozygote children being born novel mutation combinations, creating problems in the provision of accurate advice regarding the expected phenotype of the thalassaemia or haemoglobinopathy disorder. In the UK, the impact of immigration required the National Haemoglobinopathy Reference laboratory to change the strategy and techniques used for the molecular diagnosis of thalassaemia and the haemoglobinopathies. In 2005 , due to the increasingly large range of $\beta$-thalassaemia mutations that needed to be diagnosed, the laboratory switched from a three-step screening procedure using ARMS-PCR to a simpler but more expensive one-step strategy of DNA sequencing of the beta and alpha globin genes for all referrals. After ten years of employing this strategy, a further 57 novel thalassaemia and haemoglobionpopthy alleles were discovered (11 new $\beta$-chain variants, $15 \alpha$-chain variants, $19 \beta$-thalassaemia mutations and $12 \alpha^{+}$-thalassaemia mutations), increasing further the extremely heterogeneous spectrum of globin gene mutations in the UK population.
\end{abstract}

\section{Introduction}

The haemoglobinopathies are a group of autosomal recessive disorders characterised by either a reduced synthesis of one or more normal globin chains (the thalassaemias), the synthesis of a structurally abnormal globin chain (the haemoglobin variants) or in a few cases by both phenotypes (the reduced synthesis of a $\mathrm{Hb}$ variant, e.g. $\mathrm{Hb} \mathrm{E})$. As a group they are the most common single gene disorder in the world and are found at high frequencies in many populations worldwide where falciparum malaria has been or still is prevalent, due to carriers being protected against dying from malaria. More

Correspondence: John Old, John Radcliffe Hospital, Oxford, UK

This work is licensed under a Creative Commons Attribution 4.0 License (by-nc 4.0).

CC Copyright J. Old et al., 2018

Licensee PAGEPress, Italy

Thalassemia Reports 2018; 8:7474

doi:10.4081/thal.2018.7474 than one thousand different mutant alleles have at the molecular level, as described in several databases such as HbVar [1] and IthaGenes [2]. The mutations are regionally specific, dividing into four groups of countries: Mediterranean, Asian Indian, Southeast Asian, and sub-Saharan African. Each country in its group has a spectrum of abnormal haemoglobins and thalassaemia mutations, consisting of a few common alleles and a larger number of alleles found at much lower gene frequencies. The spectrum and frequency of haemoglobinopathy mutations, especially those for $\beta$-thalassaemia, have now been determined for most countries [3].

Haemoglobin disorders also occur in the native populations of some non-malarial countries, e.g. most Northern European countries, but are found at such low gene frequencies that thalassaemia and sickle cell disease were not a health problem until the last century when migration from endemic areas began to introduce these disorders to most of Northern and Western Europe. For the UK, the major immigrant populations groups were: Indian, AfroCaribbean, Pakistani, African, Bangladeshi, Cypriot, Italian and Chinese. An early study of the haemoglobinopathy mutations found in these UK consisted of a group of very rare ones specific to individuals of white British origin, such as those with a dominant $\beta$-thalassaemia phenotype, or they were mostly one of the more common mutations observed in one of the four regionally specific groups of countries described above [4].

During the last twenty years, official national statistics reveal that immigrants to the UK have come from many different countries as they flee from civil wars and military dictatorships, in particular Zaire, former Yugoslavia, Nigeria, Somalia, Sri Lanka, Iran, Syria, Iraq and Afghanistan. These new immigrant populations pose new problems for the molecular screening of $\beta$-thalassaemia mutations, as the spectrum and allele frequencies of the mutations had not been determined for some of these populations, such as the Kurdish refugees. Thus a quick screen for $\beta$-thalassaemia mutations by the cheap method of ARMS-PCR was not possible for patients from Afghanistan and Iraq, and it was found that an ever increasing number had to have a molecular diagnosis by direct sequencing of the DNA. For this reason, in 2005 the laboratory changed its molecular screening strategy for $\beta$-thalassaemia from a three-step screening procedure using ARMS-PCR [5] to a simpler but more expensive one-step strategy of routine DNA sequencing of the for $\beta$-globin genes for all referrals.

\section{Methods}

Blood samples of patients identified as presumptive haemoglobinopathy carriers using haematological techniques for the national antenatal screening program, were referred to the National Haemoglobinopathy Reference Laboratory for diagnostic confirmation and genotype identification. Each blood sample was subjected to a full blood count and quantitation of the $\mathrm{Hb} \mathrm{F}$ and $\mathrm{Hb} \mathrm{A}_{2}$ by high performance liquid chromatography system using a Bio-Rad Variant 
1 analyser. Presumptive identification and quantification of abnormal haemoglobins was carried out by both HPLC and isoelectric focusing gel electrophoresis. The HPLC retention time was recorded for each $\mathrm{Hb}$ variant peak and the isoelectric focussing distance from $\mathrm{Hb} \mathrm{A}$ was measured against known control Hbs [6].

In 2005 the molecular diagnostic strategy was changed from screening for by ARMS-PCR to routine screening of the $\beta$-globin gene. To simplify the diagnostic strategy, it was decided to also amplify the $\alpha$-globin genes routinely on all referred samples in addition to routinely screening for deletion mutations by gap-PCR or MLPA. Since the change in diagnostic strategy, approximately 12,000 DNA samples underwent PCR to selectively amplify the $\beta$-, $\alpha 1$ - and $\alpha 2$-globin genes [7]. The PCR products were cleaned up and quantified by gel electrophoresis before being subjected to cycle sequencing. The forward and reverse sequencing products were then analysed using an ABI-PRISM 3130 automated DNA analyser.

To complete the routine molecular investigations, each sample was analysed for the common 3.7 and $4.2 \mathrm{~kb}$ single $\alpha^{+}$-thalassemia globin gene deletion mutations by multiplex gap-PCR [8]. When necessary, samples were screened for larger $\alpha$ - and $\beta$-globin gene cluster deletions by gap-PCR or MLPA to investigate the possibility of $\alpha^{0}$-thalassemia, $\delta \beta$-thalassemia, deletional HPFH, $\varepsilon \gamma \delta \beta$-thalassemia, $\mathrm{Hb}$ Lepore, $\mathrm{Hb}$ Kenya and deletional $\beta$-thalassemia as previously described [9]. DNA samples that tested negative for $\alpha^{+}-$ thalassemia and associated with an $\mathrm{MCH}$ below $25 \mathrm{pg}$ were routinely screened for $\alpha^{0}$-thalassemia, and samples associated with an elevated $\mathrm{Hb} \mathrm{A} \mathrm{A}_{2}$ or raised $\mathrm{Hb} \mathrm{F}$ and a normal $\beta$-globin gene sequence were screened for $\beta$-globin gene cluster deletions.

\section{Results}

Carriers were investigated originally using a three-step diagnostic strategy in which the common $\beta$-thalassaemia mutations were screened for first by the amplification refraction mutation system ARMS-PCR with panels of primers for the common mutations, and if negative results were obtained, screened for a second time by ARMS-PCR for the rare mutations for each major ethnic group. Then any remaining uncharacterised samples were analysed by targeted DNA sequencing to identify a very rare or novel thalassemia mutation not included in the primer panels. This strategy was very successful and revealed a total of 68 different $\beta$-thalassemia mutations and 29 non-deletional $\alpha^{+}$-thalassemia mutations in the UK population [5]. A comparison of the UK spectrum of mutations to those published for 59 other countries showed that the UK had the largest number of different $\beta$-thalassaemia and non-deletional $\alpha^{+}$-thalassemia mutations.

Since 2005, more than 12,000 carriers for the antenatal screening programme have had their $\beta$-globin gene and $\alpha$-globin genes sequenced routinely by the new carrier diagnostic strategy. This has resulted in the discovery of 60 novel thalassemia and abnormal haemoglobin mutations over a period of ten years. These consisted of 11 novel $\beta$-chain variants, $15 \alpha$-chain variants, $19 \beta$-thalassaemia mutations (Table 1 ) and 15 non-deletional $\alpha^{+}$-thalassaemia mutations (Table 2) [7]. The discovery rate of novel mutations each year appears to be constant, with 29 found in the first five years and 31 in the second five year period, reflecting a continual influx of new immigrant populations to the UK over the ten year period. The large number of new thalassemia alleles discovered confirms the wide racial heterogeneity of mutations in the UK immigrant populations. This data has increased the number of known thalassaemia mutations diagnosed in UK patients to 99 different $\beta$-thalassemia point mutations, and 62 non-deletional $\alpha^{+}$-thalassemia alleles. In addition, it has resulted in an $\mathrm{Hb}$ variant library of 265 $\mathrm{Hb}$ Variants characterised by their DNA sequence, HPLC retention time and iso-electric focussing position.

The continual increase in the spectrum of known mutations is driven by the changing demographics of the UK immigrant population, with new ethnic groups such as Kurds and Iraqis entering

Table 1. Novel $\beta$-thalassaemia mutations and some haematological findings.

\begin{tabular}{|c|c|c|c|c|c|c|c|}
\hline Mutation & HGVS & $\begin{array}{c}\text { MCV } \\
\text { fl }\end{array}$ & $\begin{array}{c}\mathrm{MCH} \\
\mathrm{pg}\end{array}$ & $\begin{array}{c}\text { Hb A2 } \\
\%\end{array}$ & $\begin{array}{c}\text { Hb F } \\
\%\end{array}$ & Type & Ethnic Origin \\
\hline$-88(C \rightarrow G)$ & HBB: c. $-138 \mathrm{C}>\mathrm{G}$ & 78.3 & 21.7 & 5.6 & 5.0 & $\beta+$ & British \\
\hline$-71(\mathrm{C} \rightarrow \mathrm{T})$ & HBB: c.-121C>T & 63.8 & 20.0 & 5.5 & 5.1 & $\beta+$ & Unknown \\
\hline$-30(\mathrm{~T} \rightarrow \mathrm{G})$ & HBB: c.-80T>G & 71.7 & 23 & 4.9 & 10.2 & $\beta+$ & Unknown \\
\hline Codon 5/6 (-TG) & HBB: c.18_19delTG & 64.0 & 19.9 & 5.6 & 1.7 & $\beta$ & Turkish \\
\hline Codon 72/73 (+T) & HBB: c.219_220insT & 65.6 & 19.7 & 6.1 & 0.6 & $\beta$ & British \\
\hline Codon $90(-G)$ & HBB:c.271delG & 65.0 & 20.3 & 2.6 & 21.7 & dominant & Lithuanian \\
\hline IVSII-2 (-TGAGTCTATGGG) & HBB: c.315+2_315+13del TGAGTCTATGGG & 67.0 & 21.3 & 4.9 & 1.6 & $\beta+$ & British \\
\hline IVSII-781 C $\rightarrow \mathrm{G}$ ) & HBB: c.316-70C>C & 85.0 & 26.4 & 4.4 & 1.1 & $\beta+$ & African \\
\hline IVSII-848 C $\rightarrow \mathrm{T}$ & HBB:c.316-3C>T & 85.0 & 28.1 & 3.0 & 1.3 & $\beta+$ & Unknown \\
\hline Codon 114 (+TGTGCTG) & HBB: c.345_346insTGTGCTG & 64.0 & 19.6 & 5.4 & 1.0 & $\beta$ & Irish \\
\hline Codon $117(-\mathrm{C})$ & HBB: c.354delC & 69.0 & 20.7 & 3.8 & 6.3 & dominant & British \\
\hline Codon 124/125 (+A) & HBB: c. 375_376insA & 67.0 & 20.4 & 5.0 & 1.9 & $\beta$ & Unknown \\
\hline Codon 125 /126 (-CCAGTG) & HBB: c.376_381delCCAGTG & 78.0 & 26.0 & 3.7 & 9.6 & dominant & British \\
\hline Codon $130(\mathrm{~T} \rightarrow \mathrm{A})$ & HBB: c.393T >A & 68.0 & 17.4 & 3.5 & 1.4 & $\beta$ & Unknown \\
\hline Codon $131(+\mathrm{A})$ & HBB: c.394_395insA & 63.5 & 19.3 & 4.7 & 2.0 & $\beta$ & British \\
\hline Codon $131 \mathrm{CAG} \rightarrow \mathrm{TAG}$ & HBB:c.394C>T & 73.1 & 23.3 & 5.7 & 5.0 & dominant & British \\
\hline 3' UTR (+C, -TGGATTCT) & HBB: c. $^{*}+95_{-}^{*}+107$ delinsC & 61.0 & 18.5 & 6.0 & 1.5 & $\beta+$ & British \\
\hline Poly A (-AA) & HBB: $c^{*}+111{ }^{*}+112$ delAA & 73.6 & 23.9 & 4.0 & 0.5 & $\beta+$ & British or Irish \\
\hline Poly A $(\mathrm{A} \rightarrow \mathrm{T})$ & HBB: $c^{*}+112 A>T$ & 80.0 & 25.5 & 4.9 & 0.5 & $\beta+$ & African \\
\hline
\end{tabular}


Table 2. Novel $\alpha^{+}$-thalassaemia mutations and some haematological findings.

\begin{tabular}{|c|c|c|c|c|c|c|}
\hline Mutation & HGVS & $\begin{array}{c}\text { MCV } \\
\text { fl }\end{array}$ & $\begin{array}{c}\mathrm{MCH} \\
\mathrm{pg}\end{array}$ & $\begin{array}{c}\mathrm{Hb} \mathbf{A}_{2} \\
\%\end{array}$ & $\begin{array}{c}\mathrm{Hb} F \\
\%\end{array}$ & Ethnic origin \\
\hline$\alpha 1$ IVSI-I $(\mathrm{G} \rightarrow \mathrm{C})$ & HBAl:c. $95 \mathrm{G}>\mathrm{C}$ & 69.9 & 23.3 & 2.5 & 0.9 & Middle East \\
\hline$\alpha 1$ Codon $104(\mathrm{TGC} \rightarrow \mathrm{TGG})$ [Cys®Trp] & HBAl:c.315C>G & 79.0 & 24.8 & 3.4 & 0.2 & Pakistani \\
\hline$\alpha 1$ Codon $108(-C)$ & HBAl:c.328delC & 72.0 & 24.3 & 2.9 & 0.7 & Egyptian \\
\hline$\alpha 1$ Codon 124-128 (-13bp) & HBAl:c.333_345del & 71.0 & 21.1 & 2.4 & 0,2 & Pakistani \\
\hline$\alpha 1$ Poly A $(\mathrm{G} \rightarrow$ A) $($ AATAAAG $\rightarrow$ AATAAAA) & HBAl:c. ${ }^{*}+95 \mathrm{G}>\mathrm{A}$ & 73.4 & 24.0 & 2.7 & 1.0 & Pakistani \\
\hline$\alpha 2$ Initiation codon translation sequence (-1bp) & HBA2:c.-3delA & 73.0 & 23.1 & 2.4 & 0.3 & Indian \\
\hline$\alpha 2$ Initiation codon $(\mathrm{T} \rightarrow \mathrm{G})(\mathrm{ATG} \rightarrow \mathrm{AGG})$ & HBA2:c.2T>G & 75.3 & 23.6 & 2.9 & 3.2 & Middle East \\
\hline$\alpha 2$ Initiation codon $(\mathrm{A} \rightarrow \mathrm{T})(\mathrm{ATG} \rightarrow \mathrm{TTG})$ & HBA2:c.1A $>$ T & 79.4 & 23.3 & 2.4 & 0.3 & Southeast Asian \\
\hline a2 Codon $37(-\mathrm{C})$ & HBA2:c.114delC & 77.0 & 26.5 & 3.0 & 0.1 & British \\
\hline$\alpha 2$ Codon 47 (-A) & HBA2:c.143delA & 71.3 & 22.6 & 2.8 & 0.3 & Unknown \\
\hline$\alpha 2$ Codon 47/48 (-ACCT) & HBA2:c.143_146delACCT & 75.0 & 24.1 & 2.3 & 0.4 & British \\
\hline$\alpha 2$ Codon $51 / 52(+G)$ & HBA2:C.156_157insG & 67.0 & 22.4 & 2.9 & 0.8 & Unknown \\
\hline$\alpha 2$ Codon 73/74 (-GTGG) & HBA2:c.220_223delGTGG & 68.5 & 21.5 & 2.7 & 0.3 & Indian \\
\hline$\alpha 2$ Codon $101(\mathrm{CTA} \rightarrow \mathrm{CCA})$ [Leu $\rightarrow \mathrm{His}$ ] & HBA2:c. 305T $>C$ & 68.0 & 23.0 & 2.9 & 0.4 & Irish \\
\hline$\alpha 2$ Codon 56 (-AA) & HBA2:c. 169_170delAA & 75.4 & 24.2 & 2.8 & 0.3 & Unknown \\
\hline
\end{tabular}

the country from war zones in the Middle East, and migrants coming to the UK for temporary work from countries such as nurses from the Philippines. The impact of migration from such areas has increased significantly the range of haemoglobinopathy mutations that need to be detected in UK patients and increases the number of possible combinations and interactions of the different mutations. This creates counselling problems, as the phenotypes of these new genotype combinations have not been reported before, thus making it difficult to give accurate advice regarding outcomes in prenatal diagnosis cases. An example of this was a couple from the Philippines at risk of having a child with $\beta$-thalassaemia with the compound heterozygous phenotype of the frameshift mutation codon 67 (-TG) [c.202_203delGT] and a novel $\beta$-thalassaemia, a combination for which there was no published information which could be used to inform the parents of the probable phenotype thalassaemia major or intermedia?

\section{Conclusions}

The impact of migration of haemoglobinopathy carriers from endemic areas to a non-malarial country increases significantly the range of haemoglobinopathy mutations that need to be detected and increases the number of possible combinations and interactions of the different mutations. Thus molecular diagnostic laboratories in such countries must have the technical expertise, equipment and diagnostic strategy to detect a large variety of mutations quickly for prevention programmes based on carrier screening and prenatal diagnosis. They must also have the ability to change and adapt the molecular diagnostic strategies and technologies to address the increasing variety of mutations encountered. They must also able to provide advice on the clinical and genetic consequences of the finding novel compound genotypes from new immigrant ethnic groups for which there may be little or no published information regarding the genotype-phenotype relationship. Thus another impact of immigration on carrier screening is a requirement for staff to maintain an up to date knowledge of the thalassaemia mutations and their genotype-phenotype relationships for all ethnic groups.

The impact of migration is a driver for changing carrier screen- ing diagnostic strategy and technology. In the UK, new immigrant populations such as the Kurds, Afghanis and Iraqis entering the UK posed problems for the molecular screening of $\beta$-thalassemia mutations which were met by changing the diagnostic strategy and molecular diagnostic technology from ARMS-PCR to routine Sanger DNA sequencing of the $\alpha$-globin and $\beta$-globin genes in every sample. Analysis of the results after ten years of screening have revealed a large increase in the variety and spectrum of thalassaemia and haemoglobinopathy mutations in the UK population, confirming that the change in the screening strategy and technology was timely and necessary.

In the future, the impact of immigration will continue to drive forward changes in carrier screening strategy and technology. Indeed, a strategy of carrier screening by simply sequencing the whole alpha and beta globin gene clusters by next generation sequencing without any haematological screening has already been shown to be possible in a high-prevalence Chinese population. The authors claimed that NGS sequencing on its own was an improvement over haematological screening, no carriers were missed and some carriers were identified for which haematological screening would have diagnosed as normal [10]. However it was concluded that knowledge of haematological screening data and $\mathrm{Hb}$ pattern analysis data was still required in order to understand the importance of some of the globin gene DNA sequence changes revealed by the next generation sequencing data and thus the best carrier screening practice in the future will still require a combination of a patient's haematological data and $\mathrm{Hb}$ pattern analysis and a knowledge of thalassaemia and $\mathrm{Hb}$ variant genotype-phenotype relationships in addition to the patient's genomic sequence data.

\section{References}

1. Updates of the HbVar database of human hemoglobin variants and thalassemia mutations. Giardine B, Borg J, Viennas E, Pavlidis C, Moradkhani K, Joly P, Bartsakoulia M, Riemer C, Miller W, Tzimas G, Wajcman H, Hardison RC, Patrinos GP. Nucleic Acids Res. 2014; 42(Database issue):D1063-9. 
2. IthaGenes: An interactive database for haemoglobin variations and epidemiology. Kountouris P, Lederer CW, Fanis P, Feleki X, Old J, Kleanthous M. PLoS One. 2014; 9 (7):e103020. 1-10.

3. Henderson S, Timbs A, McCarthy J, et al. Incidence of haemoglobinopathies in various populations - the impact of immigration. Clin Biochem. 2009; 42(18):1745-1756.

4. Hall GW, Barnetson RA, Thein SL. Beta thalassaemia in the indigenous British population. Br J Haematol 1992; 82:584-8.

5. Old JM, Khan S, Verma I, et al. A multi-center study in order to further define the molecular basis of $\beta$-thalassemia in Thailand, Pakistan, Sri Lanka, Mauritius, Syria, and India, and to develop a simple molecular diagnostic strategy by amplification refractory mutation system-polymerase chain reaction. Hemoglobin. 2001; 25(4):397-407.

6. Khalil MSM, Molyneux AT, Marouf S, et al. The accurate prediction of rare hemoglobin variants using a combination of high performance liquid chromatography, retention time and isoelectric focusing electrophoresis position. Saudi Med J. 2009; 30(9):1158-1164.
7. Henderson SJ, Timbs AT, McCarthy J, Gallienne AE, Proven M, Rugless MJ, et al. Ten Years of Routine $\alpha$ - and $\beta$-Globin Gene Sequencing in UK Hemoglobinopathy Referrals Reveals 60 Novel Mutations. Hemoglobin. 2016; 40(2):75-84.

8. Liu YT, Old JM, Miles K, Fisher CA, Weatherall DJ, Clegg JB. Rapid detection of alpha-thalassaemia deletions and alpha-globin gene triplication by multiplex polymerase chain reactions. Br J Haematol. 2000; 108(2): 295-299.

9. Gallienne A, Dreau H, McCarthy J, et al. Identification of 17 different $\beta$-globin deletions (including 4 novel mutations) in the UK population by multiplex ligation-dependent probe amplification,. Hemoglobin. 2009;33(6):406-416.

10. He J, Song W, Yang J, Lu S, Yuan Y, Guo J, et al. Next-generation sequencing improves thalassemia carrier screening among premarital adults in a high prevalence population: the Dai nationality, China. Genetics in medicine: official journal of the American College of Medical Genetics. 2017; Jan 26. doi: 10.1038/gim.2016.218. [Epub ahead of print]. 